\title{
Is Yin-Yang superior for paradox research?
}

\author{
Xin Li and Verner Worm \\ Copenhagen Business School, Frederiksberg, Denmark, and \\ Peihong Xie \\ Shanghai University of International Business and Economics, Shanghai, China
}

\begin{abstract}
Purpose - The paper debunks Peter P. Li's assertion that Yin-Yang is superior to any other cognitive frames or logical systems for paradox research. The purpose of this paper is to alert the Chinese indigenous management researchers to the danger of Chinese exceptionalism and over-confidence.

Design/methodology/approach - To show that Peter P. Li's assertion is doubtful, the authors identify the flaws in his analysis.

Findings - The authors find that there are three serious flaws in Peter P. Li's analysis. First, there are four defects in the typology of cognitive frames he built in order to compare Yin-Yang with the others. Second, his understanding of dialectics in general and Hegelian dialectics in particular is flawed. And finally, without resorting to Yin-Yang, many scholars can develop theories that are equivalent to those derived from Yin-Yang. Research limitations/implications - Due to the page limit, this paper only focuses on arguing that Yin-Yang is not superior to other cognitive frames or logical systems without going one step further to explain in which situations Yin-Yang are valuable and might be more suitable than others for helping us understand some research issues.

Practical implications - This paper implies that we should not blindly believe that the Chinese way of thinking and acting is superior to other people's. Chinese people should be open-minded in the globalized era, not only promoting their own culture but also appreciating and learning from other cultures.

Social implications - The reduction of cultural exceptionalism and ethnocentrism can make cross-cultural communication and interaction smoother.
\end{abstract}

Originality/value - This paper is a rigorous critique on the "Yin-Yang being superior" assertion of Peter P. Li.

Keywords Indigenous, Paradox, Yin-Yang, Hegel, Dialectic, Superior

Paper type Viewpoint

\section{Introduction}

With the emergence of indigenous management research in China (Barkema et al., 2015; Leung, 2012; Lewin, 2014; Li, 2012a, 2014a; Li et al., 2012; Mathews and Tan, 2015; Redding, 2017; Redding and Witt, 2015; Tsui, 2004), more and more Chinese management scholars are using the Yin-Yang philosophy in their research works (e.g. Fang, 2012; Jing and Van de Ven, 2014; Lin et al., 2015; Zhang et al., 2015). As these studies have demonstrated the usefulness of Yin-Yang for analysis and theorizing, some Chinese scholars seem to have gained increasing confidence on the uniqueness and significance of Yin-Yang for Chinese indigenous management research. A notable example is Peter Ping Li who has gone so far as to assert that Yin-Yang is "superior to all" other cognitive frames or logical

(C) Xin Li, Verner Worm and Peihong Xie. Published by Emerald Publishing Limited. This article is published under the Creative Commons Attribution (CC BY 4.0) licence. Anyone may reproduce, distribute, translate and create derivative works of this article (for both commercial and non-commercial purposes), subject to full attribution to the original publication and authors. The full terms of this licence may be seen at http://creativecommons.org/licences/by/4.0/legalcode

This work was partially supported by the National Social Science Foundation of China (Grant No. 17BGL024) (in Chinese: 国家社会科学基金一般项目); the Shanghai Summit (Gaofeng) and Plateau (Gaoyuan) Discipline Project, Shanghai, China, PRC (in Chinese: 上海市高原高峰学科建设项目资助). The authors thank the action editor Kevin Au and two anonymous reviewers for their comments and suggestions. All errors remain to the authors.
Is Yin-Yang superior for paradox research?

Received 9 June 2016 Revised 21 September 2016

5 May 2017

22 June 2017

Accepted 15 November 2017

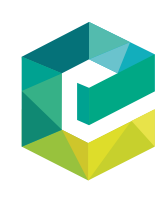

Cross Cultural \& Strategic Management
Vol. 25 No. 3,2018
pp. $501-514$ Emerald Publishing Limited 2059-5794 
CCSM

25,3

systems in dealing with management and organizational paradoxes[1] (Li, 2014, 2015a, 2015b, 2016).

Recently, Peter P. Li (2016) claims:

Even though a growing number of Western scholars have recognized the salience of paradox as well as the flaw of "either/or" logic (e.g. Ashforth and Reingen, 2014; Bobko, 1985; Smets et al., 2015; Poole and Van de Ven, 1989; Smith and Lewis, 2011), they cannot move beyond the separation-integration circle as their attempts to resolve paradox, so Yin-Yang balancing is the only epistemological system that can truly accommodate and appreciate paradox ((P.) Li, 2012a, 2014b; Smith and Lewis, 2011), and, at the same time, possesses the unique potential to embrace all Western systems into a geocentric (East-meeting-West) meta-system (p. 69, italics added).

While we agree with what Meyer (2006) has suggested that the Asian management research needs more self-confidence, we are also concerned about what Xin Li (2014a, p. 7) has warned the "danger of overconfidence" in Chinese indigenous management research. Echoing such a warning, we, in the present paper, debunk Peter P. Li's assertion that Yin-Yang is superior for paradox research by revealing three serious flaws in his analysis. First, there are four defects in the typology of cognitive frames he built in order to compare Yin-Yang with the others. Second, his understanding of dialectics in general and Hegelian dialectics in particular is flawed. And third, without resorting to Yin-Yang, many scholars have developed theories that are equivalent to those derived from Yin-Yang. The purpose of this paper is to alert Chinese scholars to the danger of Chinese exceptionalism (as critiqued by Li, 2016b; Peng, 2005) in promoting indigenous management research in China.

\section{Defects in Peter P. Li's typology of cognitive frames}

Xin Li (2014a) points out that Chinese Yin-Yang philosophy is just one of various types of dialectical thinking in the world. He builds a $2 \times 2$ typology to compare and contrast, together with Aristotle's formal logic, three particular dialectical logical systems, i.e. Yin-Yang, Hegel's dialectics, and Niels Bohr's complementarity principle. His typology is based on the differences in ontology (i.e. what the concept or object is) and epistemology (i.e. what the concept or object is seen to be) embodied in each of the four logical systems. He labels Aristotle's formal logic as "Either-Or," Hegelian dialectics as "Either-And," Yin-Yang as "Both-And," and Bohr's complementarity principle as "Both-Or" to denote their distinct ontology-epistemology characteristics. He then demonstrates that Yin-Yang is not superior to not only Hegelian dialectics and Bohr's complementarity principle but also Aristotle's formal logic.

In his response to Xin Li's analysis, Peter P. Li $(2014,2016)$ also specifies five cognitive frames or logical systems, based on two criteria, i.e. whether the logical systems recognize or deny the conflict or trade-off between opposite elements in a paradox on the one hand and the complementarity or synergy between opposites on the other. The five logical systems he specifies include: the "neither/nor" frame, defined as one denying both trade-off and synergy; the "either/or" frame, defined as one recognizing trade-off but denying synergy between true opposite elements; the "both/and" frame, defined as one recognizing synergy but denying trade-off between fake opposite elements; the "both/or" frame, defined as one temporarily recognizing but ultimately denying trade-off between temporarily true but ultimately fake opposite elements as well as temporarily denying but ultimately recognizing synergy between temporarily true but ultimately fake opposite elements; and the "either/ and" frame, defined as one always and fully recognizing both trade-off and synergy between true opposite elements.

Peter P. Li (2014, p. 324, italics added) denotes "both/or" as Hegelian dialectics while "either/and" as Yin-Yang, and then asserts "among these five cognitive frames, the Yin-Yang frame is the only frame that fully embraces paradox by recognizing and appreciating both 
trade-off and synergy between true opposite elements in the same place at the same time" while "all other four frames fail to do so," and therefore "the Yin-Yang frame is superior in managing paradoxes."

There are four defects built in Pete P. Li's (2014) classification scheme, which might be responsible for his conclusion that Yin-Yang is superior for managing paradox.

First, it is unclear, as Peter P. Li (2014) did not explain at all, what the distinctions between his so-called "temporarily true but ultimately fake opposite elements" and "true opposite elements" are, and therefore, the readers can hardly understand why, as he asserts, "only the Yin-Yang frame is capable of explaining the true opposite elements because the Yin-Yang frame is the only frame that fully recognizes and appreciates the co-existence of true opposite elements in the same place at the same time" (p. 322, italics added). Simply, such an assertion is a tautological repetition because its essence is "only Yin-Yang is capable because Yin-Yang is the only." Without clear definition of true and fake opposite elements, it functions as an convenient trick[2] that any challenge can be dismissed as fake whenever a particular paradox is shown to be well explained by any logical systems other than Yin-Yang.

Second, it is unclear what the interrelationships among the "both/and", "both/or", and "either/or" frames. On the one hand, Peter P. Li (2014, p. 322, italics added) argues "while the 'both/and' logic seems to be opposite to the 'either/or' logic, the two logical systems are ultimately consistent with each other. This is because the 'both/and' logic can accept the co-existence of 'fakely' conflicting, but truly complementary, elements, which is consistent with the 'either/or' logic." On the other hand, Peter P. Li (2016, p. 47, italics added) argues "As an alternative to Aristotle's formal logic, Hegel's dialectical logic appears to accept and embrace paradox. However, the emerging view is that the dialectical logic is superficially incompatible, but fundamentally consistent, with Aristotle's formal logic, due to the shared goal of paradox resolution" because "Hegel's 'both/or' system also avoids and denies the ultimate possibility of paradox, so it is fundamentally compatible with Aristotle's 'either/or' logic." So, it is unclear whether these three frames are all consistent or compatible to each other.

Third, there is no consistent rule in his selection of labels for the five cognitive frames. In the case of "neither/nor", Peter P. Li seems to use the words "neither" and "nor" as conjunction words because he defines the "neither/nor" frame as denying both trade-off and synergy, which can be reinterpreted as recognizing neither (trade-off) nor (synergy). Clearly, the "neither/nor" phrase can be separated to be used as conjunction words. But, in the cases of "either/or" and "both/and", he seems to use both labels as inseparable phrases, which are used as pronouns because "either/or" is defined as recognizing trade-off but denying synergy while "both/and" as recognizing synergy but denying trade-off. Clearly, either/or is associated here with trade-off while both/and with synergy. Unfortunately, this inconsistence in label selection rule is a fundamental problem for two reasons.

The first, if he followed the same rule used in defining the "neither/nor" frame, i.e. using the label as conjunction words, then the "either/or" frame should have been defined as recognizing either (trade-off) or (synergy), or more precisely, either (recognizing trade-off but denying synergy) or (recognizing synergy but denying trade-off), and the "both/and" frame should have been defined as recognizing both (trade-off) and (synergy).

The second, if he followed the same rule used in defining "either/or" and "both/and," i.e. using the labels as pronouns, then the "both/or" and the "either/and" labels should have had almost identical meanings because both of them are a combination of "either/or" and "both/and" while the only difference is which one of the two (i.e. "either/or" and "both/and") takes the first half of the combinative label (i.e. "either/and" or "both/or"). To further distinguish the two combinative labels, an additional rule for defining is needed.

Peter P. Li does provide some extra explanation of the "both/or" label, namely, he defines it as a cognitive frame "temporarily recognizing, but ultimately denying, trade-off between temporarily true but ultimately fake opposite elements; temporarily denying, but ultimately
Is Yin-Yang superior for paradox research? 
CCSM

25,3

504

recognizing, synergy between temporarily true but ultimately fake opposite elements" (Li, 2014, p. 324). However, he fails to consistently apply such an extra "temporarily recognizing but ultimately denying" rule to the definition of "either/and." In addition, while he seems to use "either/or" and "both/and" as pronouns in defining "either/and" (i.e. always and fully recognizing both trade-off and synergy between true opposite elements), he fails to consistently apply this rule when defining "both/or" (i.e. temporarily recognizing but ultimately denying trade-off and temporarily denying but ultimately recognizing synergy).

In sum, Peter P. Li seems to be arbitrary in defining or labeling the five cognitive frames he specifies. It seems that he has not realized the need for a consistent logic in analyzing the logical systems.

Finally, as a direct consequence of the inconsistent rule or logic problem, Peter P. Li fails to make a nuanced and complete classification of logical systems. As his "either/and" and "both/or" labels are combinations of elementary logical systems such as "either/or" and "both/and," there might be other possible combinations, such as "either/nor" and "neither/ and," that are not incorporated in his classification scheme.

In response to Peter P. Li's (2014) problematic classification scheme, Xin Li (2014b) proposes a $3 \times 3$ typology to incorporate nine possible logical systems[3] based on two dimensions, i.e. the means (or behavior) and the end (or consequence) stressed in a logical system (see Figure 1). This expanded typology uses a consistent combinative "means-end" or "cognition-behavior" structure as the rule for labeling logical systems. For instance, the label of "Both-Or" indicates using "both/and" as a means to reach the end of "either/or" while "Either-And" indicates using "either/or" as a means to reach the end of "both/and." Designed in this way, all the nine labels in this typology are combinative, and such a "means-end" combination ensures self-evident distinctions between pairs such as "both-or" and "either-and" and "neither-and" and "both-nor."

Building on Xin Li’s (2014b) $3 \times 3$ typology, Li et al. (2015) identify five logical systems that are useful for solving paradox. These five logical systems correspond to the five cells in between the four corner cells. The five cells are useful for solving paradox because each of them has a "both/and" element while the four cornered cells do not. It is beyond the scope of the present paper to explain how these five logical systems can be used for analyzing paradox in general, it has been demonstrated by Li et al. (2015) that all of them can help us understand and manage a particular paradox, i.e. the cost leadership vs differentiation paradox.

\section{Peter P. Li's understanding of (Hegelian) dialectics is flawed}

While many Chinese view Yin-Yang as a primitive[4] or "naïve" (Peng and Nisbett, 1999) form of dialectical thinking, Peter P. Li (2014, pp. 321-322) claims that it was his past mistake "to regard the Yin-Yang frame as the Chinese version of dialectical thinking to address paradoxes" and since 2008 he has corrected that mistake by realizing that "the Yin-Yang frame is not a dialectic type" (p. 325, italics added). Peter P. Li (2014) does not explicitly explain why he thinks Yin-Yang is not a dialectical type of thinking, for which Peter P. Li (2016) provides a clue.

Peter P. Li seems to be influenced by Peng and Nisbett's (1999) study of cross-cultural differences on reasoning about contradiction, which, according to Ho (2000, p. 1064), "is marked by logical and empirical flaws." In our view, the most fundamental flaw is that, while Peng and Nisbett (2000, p. 1067) "intended to be inclusive", they nevertheless narrowly define "The Western dialectical thinking styles" as "the Hegelian and Marxist styles." What is worse, they mistakenly treat Hegelian and Marxist dialectics as the same and assert the two "are fundamentally consistent with the laws of formal logic and are aggressive in the sense that contradictions require synthesis rather than mere acceptance."

Xin Li (2016b) points out it has been a commonly held misunderstanding of Hegelian dialectics, among management scholars as well as professional philosophers (cf. Mueller, 1958), 


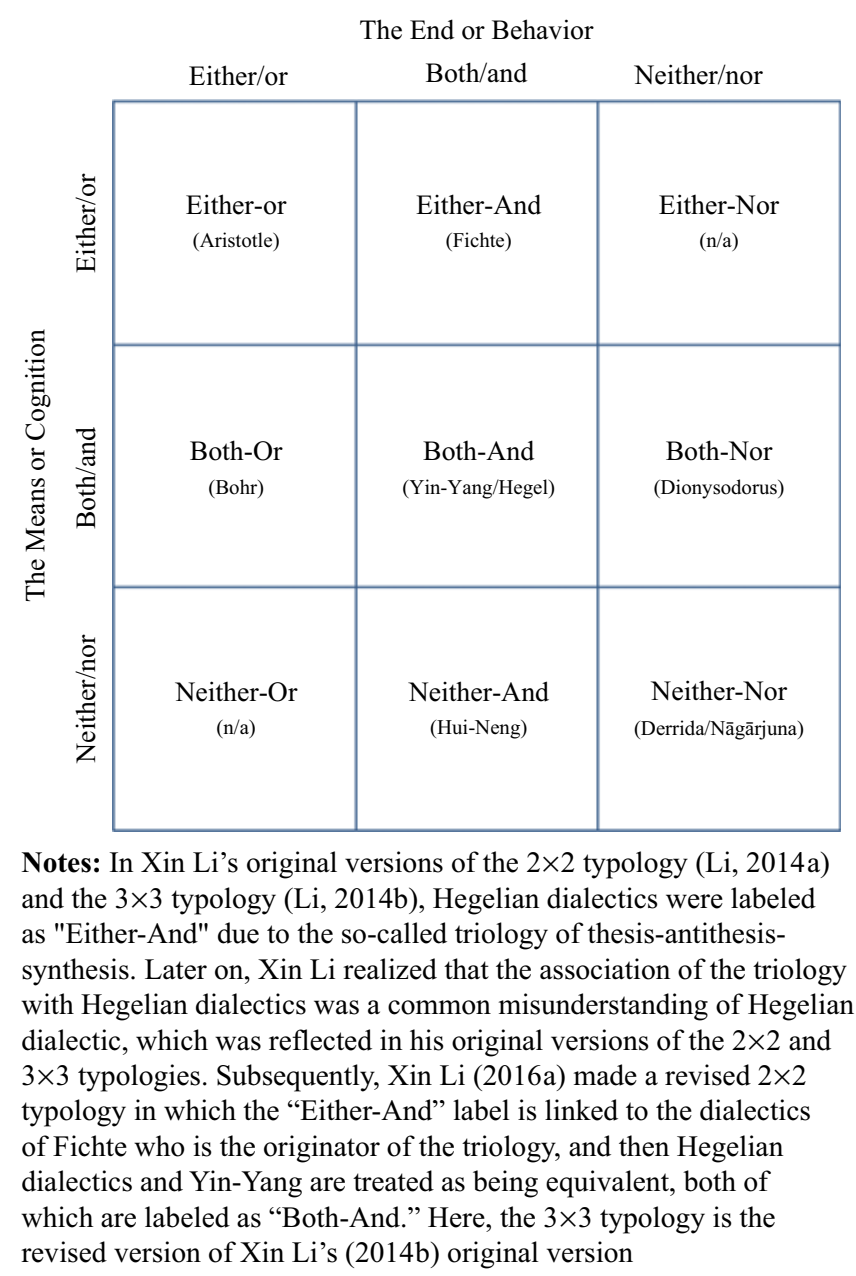

Source: Adapted from Xin Li (2014b)
Is Yin-Yang superior for paradox research?

505

that Hegelian dialectics does not accept or strives for resolving contradiction. More specifically, many people misunderstand Hegelian dialectics as the triology of thesis-antithesis-synthesis; and as synthesis is a sort of reconciliation of the contradiction between thesis and antithesis those people believe that Hegelian dialectics strives for resolving contradiction. However, as Mueller (1958) points out, Hegelian dialectics is not about the trilogy of thesis-antithesis-synthesis, a method originated by Fichte[5] and later explicated by Schelling, of both of which Hegel was a contemporary.

In fact, Hegelian dialectics should be seen as quadruplicity rather than triplicity, as Hegel (1969) himself pointed out in the Section $\S 1801$ of his Science of Logic:

It is also, however, the third term to the first or formal negative and to absolute negativity or the second negative; now as the first negative is already the second term, the term reckoned as third can also be reckoned as fourth, and instead of a triplicity, the abstract form may be taken as a quadruplicity; in this way, the negative or the difference is counted as a duality. The third or fourth is in general the unity of the first and second moments, of the immediate and the mediated. 
CCSM

25,3

Understood as a quadruplicity, Hegelian's dialectics are almost equivalent to Yin-Yang, in terms of the structural relationship between the opposites. In Yin-Yang, any entity has two opposite sub-elements, i.e. yin and yang, each of which has its own two opposite sub-elements. The interaction between the two opposites will enable the mutual transformation between or coevolution of the two original yin and yang opposites into a new pair of yin and yang opposites. Therefore, Yin-Yang entails a quadruplicity structure, i.e. transformation or coevolution of two original yin and yang opposites into a new pair of yin and yang opposites. In Hegelian dialectics, the two original opposites, i.e. being and nothing, will go through the process of sublation (becoming)[6] that results in transformation or coevolution of two original being and nothing opposites into a new pair of opposites. This is evident from what Hegel writes in the Section $\S 134$ of his Science of Logic:

Pure Being and pure nothing are, therefore, the same. What is the truth is neither being nor nothing, but that being - does not pass over but has passed over - into nothing, and nothing into being. But it is equally true that they are not undistinguished from each other, that, on the contrary, they are not the same, that they are absolutely distinct, and yet that they are unseparated and inseparable and that each immediately vanishes in its opposite. Their truth is therefore, this movement of the immediate vanishing of the one into the other: becoming, a movement in which both are distinguished, but by a difference which has equally immediately resolved itself.

However, there are three important differences between Peng and Nisbett's (2000) argument and Peter P. Li's $(2014,2016)$ assertion that Yin-Yang is not a dialectical type. First, while Peng and Nisbett (2000, p. 1067, italics in original) "used the term dialectical thinking in a rather broad way to refer to a cluster of concepts [...] intended to be inclusive" so that they can speak of Western and Eastern [Chinese] dialectical thinking, Peter P. Li (2016) limits dialectical thinking to a type of Western thinking and then equates the latter to Hegel's dialectics. Second, while Peng and Nisbett (2000, p. 1067) acknowledge "Whether the sorts of Chinese reasoning tendencies that we described should be termed dialectical we regard as an open question", Peter P. Li (2014, p. 325, italic added, 2016) makes a firm conclusion "the Yin-Yang frame is not a dialectic type." Third, while Peng and Nisbett (2000, p. 1067, italics added) are quite modest in making their argument that "That there are clear similarities between Eastern and Western dialecticism, but the differences may be great enough that using the same term for both may prove to be more confusing than helpful," Peter P. Li (2016, p. 47) is absolute by adding the word "truly" when quoting Peng and Nisbett (2000) that "it is truly "more confusing than helpful" to frame Yin-Yang balancing as dialectical (p. 1067)."

Closely examining Peter P. Li's $(2014,2016)$ analyses, we can detect two false assumptions underlying his assertion that Yin-Yang is not dialectical thinking. The first one is that the dialectical tradition in the West is based on Hegel's dialectical logic, which is evident in the following quotation:

[...] there are two core epistemological systems in the West. The first is a mechanistic system [...] [based on] Aristotle's formal formal logic as the "either/or" [...] The second core system in the West is a revised mechanistic system [...] This is Hegel's dialectical logic as the "both/or" system'. Peter P. Li (2016, p. 47) claims that "the dialectical logic is superficially incompatible, but fundamentally consistent, with Aristotle's formal logic, due to the shared goal of paradox resolution [...] Hegel's 'both/or' system also avoids and denies the ultimate possibility of paradox, so it is fundamentally compatible with Aristotle's 'either/or' logic" (Li, 2016, pp. 46-47, italics added).

This assumption is false because there exist many different dialectical thinking in the West (Lee, 2000; Wong, 2006), e.g. Heraclitus', Plato's, Kant's, Fichte's, Schelling's, Hegel's, Marx, Engels, Nietzsche's, and Adorno's (1973), etc. It is worth noting that Peng and Nisbett (2000, p. 1067) seem to equate "dialectical fashion" to "[to] propose a [hegelian] synthesis that may resolve some of the seeming contradictions," which shows they may also share such a false assumption of Peter P. Li's. 
The second assumption is that Hegelian dialectics deny contradiction being intrinsic to things and resolves contradiction, which is evident in the following quotation:

[...] the central distinction between Yin-Yang balancing and Hegel's dialectic logic lies in three critical aspects. First, while Hegel's dialectic logic treats paradox as only temporarily necessary to be resolved ultimately [...] Yin-Yang balancing fully embraces paradox as permanently necessary [...]. Second, Yin-Yang balancing also rejects the dialectical notion of absolute negation [...]. Third, Yin-Yang balancing frames the tradeoff and synergy between opposite elements as endogenous because each opposite contains the "seed" of the other opposite, while Hegel's dialectic logic assumes such tradeoff and synergy as exogenous with each opposite starting as a separate entity with a full identity. Hence, the system of Yin-Yang balance differs from Hegel's dialectical logic in fundamental ways, and it is the only system available to truly and fully appreciate and accommodate opposites (Li, 2016, pp. 53-54, italics added).

This assumption is also false because, unlike what Peter P. Li asserts, Hegelian dialectic, as expressed in the Introduction and first chapter of his Science of Logic, not only recognizes that contradiction is intrinsic to things but also sees contradiction being eternal.

Peter P. Li (2016, p. 59) argues "the system of Yin-Yang balancing possesses the unique attribute of explaining paradox by reframing paradox into duality as opposites-in-unity [...]. In contrast, all the other four systems fail to do so." This means Peter P. Li sees the essence and uniqueness of Yin-Yang being "opposites-in-unity." However, Lenin (1976)[7], in his Philosophical Notebooks, after his careful reviews of Hegel's Science of Logic, points out, "In brief, dialectics can be defined as the doctrine of the unity of opposites. This embodies the essence of dialectics" (p. 222), which is "The splitting of a single whole and the cognition of its contradictory parts [...]. That is precisely how Hegel, too, puts the matter" (p. 357). This means any philosophical system examining the unity of opposites, such as Yin-Yang understood by Peter P. Li, can be categorized as a form of dialectical thinking.

Peter P. Li (2016) argues that "Yin-Yang balancing" has three core tenets, i.e. holistic content, dynamic process, and duality balance. However, these tenets are not unique to Yin-Yang as a type of dialectical thinking because Hegelian dialectics have equivalent ideas. Lenin (1976, pp. 220-222) lists 16 elements of (Hegelian) dialectics that fully cover all the three tenets of Peter P. Li's "Yin-Yang balancing."

\section{Without resorting to Yin-Yang, people can develop equivalent theories}

Peter P. Li (2016, p. 69) asserts that without using Yin-Yang Western scholars "cannot move beyond the separation-integration circle as their attempts to resolve paradox." However, the reality is, without resorting to Yin-Yang, people, both Chinese and Westerners, can develop equivalent theories to those derived from Yin-Yang. We will provide three Chinese examples and three Western examples, respectively.

\section{The three Chinese examples}

In responding to Pope and Meyer's (2015) convergence thesis that global business practices will converge to that of the global corporate organization, both Li and Ma (2015) and Peter P. $\mathrm{Li}(2015 \mathrm{~b})$ make an essentially same "convergence as well as divergence" counterargument to that of Pope and Meyer's. While Peter P. Li's (2015b) argument is solely an application of Yin-Yang, Li and Ma's (2015) analysis is purely based on the West-based institution theory and upper echelon theory.

Xueguang Zhou (2012, 2013), a Stanford-based Chinese Sociologist, in his studies of state governance in China, applies mainstream west-based theories, such as institutional theory and Max Weber's theories of power and bureaucracy, to analyze the paradoxical relationships between the state and the bureaucracy, between central and local governments, and between mobilizational and bureaucratic mechanisms of governance.
Is Yin-Yang superior for paradox research? 
CCSM

25,3

Although Zhou does not utilize the Yin-Yang philosophy, his analyses are nevertheless in full spirit of Yin-Yang.

Mike Peng (2003) adopts an economic, i.e. marginal cost and marginal benefit analysis, approach to address the question how organizations make strategic choices during the time of fundamental institutional transitions from a relationship-based, personalized transaction structure calling for a network-centered strategy to a rule-based, impersonal exchange regime suggesting a market-centered strategy. His two-phase model of institutional transitions is fully in alignment with a Yin-Yang approach, although he does not mention Yin-Yang at all.

\section{The three Western examples}

Burgelman and Grove (2007), in their study of strategy-making at Intel, propose a balanced process that matches induced and autonomous processes to strategic dynamics situations. The Table 4 in their article embodies the three core tenets of Yin-Yang that Peter P. Li identifies as well as the three operating mechanisms Peter P. Li stipulates, i.e. asymmetrical balance[8], curvilinear balance, and transitional balance.

Oscar Ichazo (1982), a Bolivian-born Philosopher, proposes a new logic, trialectics, that "goes beyond formal logic and dialectics" (Bahm, 1984, p. 205), which is viewed as a practical[9] logic of unity by Horn (1983). Although Ichazo (1982, p. 62) associates his trialectics to "physics of Plank, Einstein, and Bohr[10]," in our view, this new logical system has, in many respects, resemblance with the ideas of cyclical change of Chinese classical book I-Ching (the Book of Change) from which Chinese Yin-Yang philosophy was derived. This is evident from following viewpoints: "Everything is the seed of its apparent contray" (Ichazo, 1982, p. 63); "everything is in change" (p. 72); "all changes [...] are cyclical" (p. 72); "Fundamental to trialectics is the notion that all is process; there are no things in the universe other than processes" (cited in Ford and Backoff, 1988, p. 99); "Energy moves in a universe with pre-established laws [...]. The perpetual motion of all creation is due to the interchange of energy [...] [The] universe is permanently changing, and the laws of change never change" (cited in Bahm, 1984, p. 205; cf. Tsoukas and Chia, 2002).

Smets et al. (2015), in their study of reinsurance trading in Lloyd's of London, propose a holistic and dynamic model of balancing conflicting-yet-complementary logics in practice. Their solution to the belonging paradox (i.e. the reinsurance underwriter's dual identity of being a part of the financial market as well as the Lloyd's community) is to specify three interrelated mechanisms, i.e. segmenting, bridging, and demarcating (SBD). In what follows, we show how Smets et al.'s SBD model can be used to derive the Yin-Yang symbol with some creative imagination (see Figure 2)[11].

The creative imagination in drawing the Figure 2 is embodied in several special designs. First, the entire drawing must be made within a circle. Second, "segmenting" is taken to mean a division of the whole into two identical parts, being half circle-shaped or comma-shaped. Third, "bridging" is denoted by dashed half circle line within a half-circle-shaped part or dashed full circle within a comma-shaped part. Fourth, "demarcating" is shown by making the dashed lines into solid ones. The rationale for this particular interpretation of demarcating is that one aspect of the mechanism of demarcating defined by Smets et al. is delimiting the boundary or confining bridging within a zone or degree of appropriateness.

From Figure 2, we can see that a Yin-Yang symbol can be derived after only two rounds of the SBD process. In the first round, segmenting is done by dividing the circle into two identical parts, i.e. two half circle-shaped parts. Then, bridging is done by drawing two half circle lines within the two half circle-shaped parts. The two-dashed lines are placed in opposite positions to make rotated mirror images. And finally, demarcating is executed by changing the two-dashed lines into solid ones. 


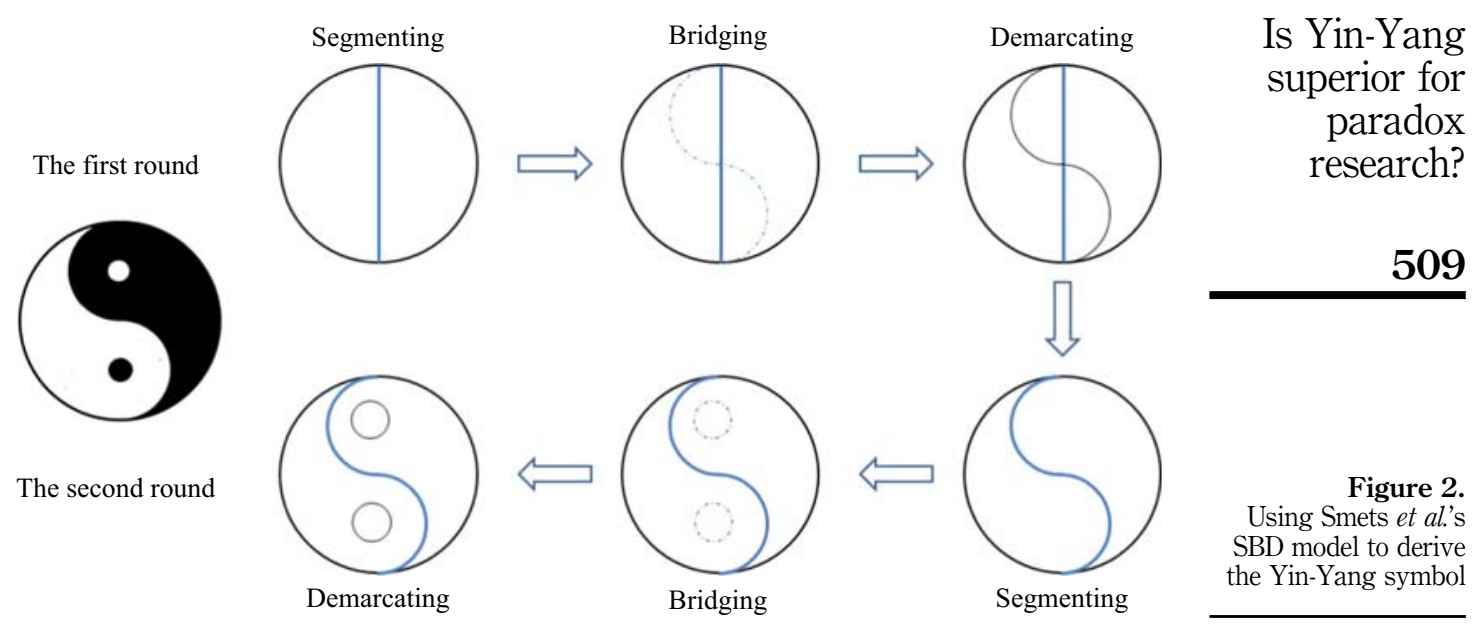

In the second round, the act of segmenting is to divide or transform the final drawing at the end of the first round into two identical parts. There might be different ways of division. However, in order to derive the Yin-Yang symbol, the creativity needed is to delete the vertical line and then to use the two solid half circle lines, now connected into an S curve, as the dividing line. Then the entire circle is divided into two comma-shaped identical parts. Then, bridging is done by drawing two-dashed full circles in the newly formed two identical parts. And finally demarcating is shown by changing the two dashed lines into solid ones. At the end of the second round of segmenting-bridging-demarcating process, a Yin-Yang shape is derived.

In sum, without resorting to Yin-Yang, people, both Chinese and Westerners, can develop equivalent theories.

\section{Conclusion}

Above, we have explained why Yin-Yang in general and Peter P. Li's "Yin-Yang balancing" solution in particular are not superior for paradox research.

We alert Chinese indigenous management researchers to the danger of Chinese exceptionalism (as critiqued by Peng, 2005), which may prevent one from seeing the fact that the West has many equivalent ideas to those often associated with the Chinese culture (Redding, 2017), such as Yin-Yang, Zhong-Yong, and harmony.

For example, Lee (2000, p. 1066, italics in origin) point out:

There is a great possibility that dialectical reasoning and thinking (or paradoxical logic) may be culturally universal (or etic and general), not culturally unique (or emic and specific) to Chinese or East Asians [...] is dialectical reasoning (or paradoxical logic) unique to Chinese or East Asians? Is Western thinking Aristotelian? The answer to these questions may be yes and no (i.e. dialectical) or it depends. It is yes, as can be seen in Peng and Nisbett's (1999) findings [...] It is no because many Westerners, especially European philosophers, also have a tradition of dialectical thinking and reasoning about contradiction, for example, Heraclitus, Immanuel Kant, Georg Wilhelm Friedrich Hegel, Karl Marx, Frederick Engels, and Friedrich Nietzsche [...] other evidence of paradoxical or dialectical thinking can be seen beyond Europe and China. In ancient Indian philosophy, Brahmanic thinking was concerned with the unity or harmony based on two opposites (Lee $e$ t al., 1999). Opposition is a category of the human mind, not in itself an element of reality.

In addition, Aristotle's Doctrine of the Mean can be said to be essentially same as Chinese Zhong-Yong as Aristotle's Mean is not arithmetic mean but a mean "relative to us" 
CCSM

25,3

(Losin, 1987). Harmony, as a value, is also not unique to the Chinese culture, as Nadar (1990) and Brew (2007) link harmony to Christianity. For example, in the New Testament, Peter 3:8 instructs: "Finally, all of you, live in harmony with another; be sympathetic, love as brothers, be compassionate and humble" (International Bible Society, 1984, cited in Brew, 2007, p. 44).

More interestingly, even the Chinese Yin-Yang symbol has an exact equivalent in the insignia of the Roman Empire (Monastra, 2000)[12]. In fact, the Roman yin-yang-like symbol appeared several centuries before Chinese Yin-Yang symbol did.

In conclusion, we echo Yadong Luo's (2016, italics added) recent call for "reverse adaptation," that is, for local people to learn, assimilate, and modify their personal behavior (e.g. values, norms, habits) and professional competence (e.g. standards, goals, language, knowledge, capabilities) in order to fit global mindset and culture. We strongly believe what Chinese academia in general and Chinese indigenous management research in particular need is not pride and prejudice but patience and modesty.

\section{Notes}

1. It is ironic that while Peter P. Li (2012a, b, p. 857) rejects the "implicit, but questionable, assumption' of the superiority of Western theories and argues the Western etic perspective and indigenous emic perspective are 'equally valid and equally critical' (p. 870), he nevertheless claims the superiority of Yin-Yang as a cognitive frame over all other ones.

2. Peter P. Li (2016, p. 61, italics added) also applies a similar trick when he claims "other Western scholars implicitly apply Yin-Yang balancing. For example, in their study of over 1,000 western firms, Dodd and Favaro (2006) concluded that those firms that adopted a more balanced approach to three pairs of opposite goals (i.e. profitability vs growth, short term vs long term, and whole vs parts) performed better than those firms that were less balanced." The trick is that, when a westerner comes up with a solution to paradox without resorting to Yin-Yang, Peter P. Li can claim he or she has implicitly applied Yin-Yang without awareness, which is non-falsifiable.

3. Xin Li initially conceived of the idea of nine possible combinative logics in November 2008 when taking his $\mathrm{PhD}$ course on "Philosophy and Management" at Copenhagen Business School. He got the inspiration after reading Barbara Johnson's (1989) book A World of Difference that writes "Instead of a simple 'either/or' structure, deconstruction attempts to elaborate a discourse that says neither 'either/or,' 'both/and' nor even 'neither/nor,' while at the same time not totally abandoning these logics either." Interestingly, Ichazo (1982, p. 90) claims that "In reality, humanity has developed nine types of logic. We only know the seventh and eighth: formal (Aristotelian) logic, and dialectical (Hegelian) logic. Now with trialectics, which is the ninth, we reach the top." Unfortunately, Ichazo did not explain what the other six logics are except saying that "before the logic of Aristotle...humanity had already been thinking... with a different logic, the logic of magic." Inspired by these discussions, Xin Li formally developed and presented his $3 \times 3$ typology of nine possible logical systems in a conference held in Wuhan, China on February 28, 2014. A summary of the conference and Xin Li's talks at the conference can be found in Cao and Song (2014).

4. We use two criteria to judge whether a philosophical idea or system of ideas is more primitive or advanced relative to another one: has it gone through a process of negation of negation, and has its development been informed by the advancement of scientific knowledge. We use the word 'primitive' here in the same sense as Lenin (1976, p. 492) describes Hobbes' materialism as "primitive materialism." Therefore, to say Yin-Yang is primitive relative to Hegelian dialectics is like to say Heraclitus' dialectical thinking is primitive relative to Hegelian. In addition, the core philosophical categories of Chinese Yin-Yang philosophy, such as yin, yang, and qi, are life world words and less abstract than notions such as "being," "essence," "subjectivity," "objectivity," and "idea" of Hegelian dialectics.

5. Thomas McFarland (2002, p. lxxxvi), in his Prolegomena to Coleridge's Opus Maximum, identifies Kant's (1781/1998) Critique of Pure Reason as the genesis of the dyad, i.e., thesis and 
antithesis, and points out it is Fichte in his 1794 book Grundlage der gesammten Wissenschaftaslehre (Foundations of the Science of Knowledge) (1794) took up Kant's repeated use of the concept of synthesis and used it to resolve the thesis-antithesis dichotomy, and therefore invented the trilogy of thesis-antithesis-synthesis, which is further developed by Schelling into a pyramidal form.

6. It is worth noting that the process of becoming or sublation in Hegelian dialectics has two opposite sub-processes, i.e., coming-to-be and ceasing-to-be. Hegel writes in the Section $\S 187$ of his Science of Logic, "Being and nothing are the same; but just because they are the same they are no longer being and nothing, but now have a different significance. In becoming they were coming-to-be and ceasing-to-be."

7. We cite Lenin's analysis on Hegelian dialectics because many Chinese people's knowledge of Hegelian dialectics are taught by communist education of Marxism-Leninism.

8. We do not agree with Peter P. Li's asymmetrical balance as a prescriptive rule of Yin-Yang, which is ironically anti-Yin-Yang, because, according to the Yin-Yang logic, namely, if there is a yin (asymmetrical balance), there must be a corresponding yang (symmetric balance), we can say that, Yin-Yang not only allows but ensure the co-existence of both asymmetric and symmetric balances.

9. It is indeed proposed with practical reason as Ichazo (1982, p. 65) argues "Only a common logic that works in our surrounding universe, that works in society, and that works for individuals, will achieve the real purpose of history - to accomplish happiness for all."

10. Bobko (1985, p. 105) takes Bohr's (1934) notion of complementarity as an example of non-bipolar resolution to wave-particle paradox of light.

11. We choose to derive a Yin-Yang symbol by creatively interpreting a West-based model to visualize our argument that a West-based theory can be equivalent to one deduced from Yin-Yang.

12. The Roman yin-yang-like symbol can be found in an article published online at: http:// saggezzaatemporale.altervista.org/estovest.net/tradizione/yinyang_en.html (accessed November 15, 2017). In this online article, Figure 1 shows a photo of the insignia of the Roman Empire, in which the third symbol on the row of "76-79" is a yin-yang-like one.

\section{References}

Adorno, T. (1973), Negative Dialectics, Routledge, London.

Ashforth, B.E. and Reingen, P.H. (2014), "Functions of dysfunction: managing the dynamics of an organizational duality in a natural food cooperative”, Administrative Science Quarterly, Vol. 59 No. 3, pp. 474-516.

Bahm, A.J. (1984), "Trialectics: toward a practical logic of unity”, in Horn, R.E. (Ed.), Information Resources, Lexington, MA.

Barkema, H.G., Chen, X.P., George, G., Luo, Y. and Tsui, A.S. (2015), "West meets East: new concepts and theories”, Academy of Management Journal, Vol. 58 No. 2, pp. 460-479.

Bobko, P. (1985), "Removing assumptions of bipolarity: towards variation and circularity", Academy of Management Review, Vol. 10 No. 1, pp. 99-108.

Bohr, N. (1934), Atomic Physics and the Description of Nature, Cambridge University Press, Cambridge.

Brew, F.P. (2007), "Harmony and controversy: the Yin and Yang of conflict in East Asian and Western cultures”, in Liu, J.H., Ward, C., Bernardo, A., Karasawa, M. and Fischer, R. (Eds), Casting the Individual in Societal and Cultural Contexts: Social and Societal Psychology for Asia and the Pacific, Kyoyook-Kwahak-Sa Publishing Company, Seoul, pp. 39-59.

Burgelman, R.A. and Grove, A.S. (2007), "Let chaos reign, then rein in chaos - repeatedly: managing strategic dynamics for corporate longevity”, Strategic Management Journal, Vol. 28 No. 10, pp. 965-979.

Is Yin-Yang superior for paradox research? 
CCSM

25,3

512

Cao, Z. and Song, S. (2014), "Path exploration and scientific attempts for indigenous management research in China: a review of the 2014 symposium on the status and prospects of indigenous management research in China (in Chinese: 中国本土管理研究路径探索与科学尝试—2014 “中国本土管理研究的现状与展望”研讨会述评)”, Chinese Journal of Management (in Chinese: 管理学报), Vol. 11 No. 5, pp. 641-644.

Dodd, D. and Favaro, K. (2006), "Managing the right tension”, Harvard Business Review, Vol. 84 No. 12, pp. 62-74.

Fang, T. (2012), "Yin Yang: a new perspective on culture", Management and Organization Review, Vol. 8 No. 1, pp. 25-50.

Ford, J.D. and Backoff, R.W. (1988), "Organizational change in and out of dualities and paradox", in Quinn, R.E. and Cameron, K.S. (Eds), Paradox and Transformation: Towards a Theory of Change in Organization and Management, Balinger Publishing, Cambridge, MA, pp. 81-121.

Hegel, G.W.F. (1969), Science of Logic (Trans. by A.V. Miller), George Allen \& Unwin, London (originally first published in 1812).

Ho, D.Y. (2000), "Dialectical thinking: neither eastern nor western”, The American Psychologist, Vol. 55 No. 9, pp. 1064-1065.

Horn, R.E. (1983), Trialectics: Toward a Practical Logic of Unity, Lexington Institute, Lexington, MA.

Ichazo, O. (1982), Between Metaphysics and Protoanalysis, Arica, New York, NY.

Jing, R. and Van de Ven, A. (2014), "A Yin-Yang model of organizational change: the case of CBG", Management and Organization Review, Vol. 10 No. 1, pp. 55-80.

Johnson, B. (1989), A World of Difference, John Hopkins University Press, Baltimore, MD.

Kant, I. (1781/1998), Critique of Pure Reason (Trans. by Paul Guyer and Allen Wood), Cambridge University Press, Cambridge.

Lee, Y.T. (2000), "What is missing in Chinese-western dialectical reasoning?", The American Psychologist, Vol. 55 No. 9, pp. 1065-1067.

Lee, Y.T., McCauley, R. and Draguns, J. (1999), Personality and Person Perception Across Cultures, Erlbaum, Mahwah, NJ.

Lenin, V.I. (1976), Philosophical Notebooks (Trans. by C. Dutt and S. Smith), Lenin Collected Works, Vol. 38, Progress Publishers, Moscow, available at: www.marx2mao.com/PDFs/Lenin \%20CW-Vol.\% 2038.pdf

Leung, K. (2012), "Indigenous Chinese management research: like it or not, we need it", Management and Organization Review, Vol. 8 No. 1, pp. 1-5.

Lewin, A.Y. (2014), "Emerging economies open unlimited opportunities for advancing management and organization scholarship”, Management and Organization Review, Vol. 10 No. 1, pp. 1-5.

Li, P.P. (2012a), "Toward an integrative framework of indigenous research: the geocentric implications of Yin-Yang balance", Asia Pacific Journal of Management, Vol. 29 No. 4, pp. 849-872.

Li, P.P. (2012b), "Exploring the unique roles of trust and play in private creativity: from the complexityambiguity-metaphor link to the trust-play-creativity link", Journal of Trust Research, Vol. 2 No. 1, pp. 71-97.

Li, P.P. (2014), "The unique value of Yin-Yang balancing: a critical response", Management and Organization Review, Vol. 10 No. 2, pp. 321-332.

Li, P.P. (2015a), "The economic-social duality for executive rationale: the interplay between resource pool and game rule for sense-giving and sense-making", Management and Organization Review, Vol. 11 No. 2, pp. 211-216.

Li, P.P. (2015b), "Both converging toward and diverging from global paradigms: the perspective of Yin-Yang balancing for the unity-in-diversity duality", Management and Organization Review, Vol. 11 No. 4, pp. 807-813. 
Li, P.P. (2016), "Global implications of the indigenous epistemological system from the East: how to apply Yin-Yang balancing to paradox management", Cross Cultural \& Strategic Management, Vol. 23 No. 1, pp. 42-77.

Li, P.P., Leung, K., Chen, C.C. and Luo, J.-D. (2012), "Indigenous research on Chinese management: what and how", Management and Organization Review, Vol. 8 No. 1, pp. 7-24.

Li, X. (2014a), “Can Yin-Yang guide Chinese indigenous management research?”, Management and Organization Review, Vol. 10 No. 1, pp. 7-27.

Li, X. (2014b), “About the debate on Yin-Yang: a reply to Professor Peter P. Li (in Chinese: 关于阴阳的 辩论: 答李平教授)”, paper presented on the International Symposium on “The Status and Prospects of Indigenous Management Research in China” (in Chinese: “中国本土管理研究的现 状与展望”国际研讨会), Wuhan, February 28.

$\mathrm{Li}, \mathrm{X}$. (2016a), "Modesty or overconfidence: on the attitude of Chinese indigenous management research (in Chinese: 谦虚谨慎或者骄傲自负: 中国本土管理研究的心态问题)”, Chinese Journal of Management (in Chinese: 管理学报), Vol. 13 No. 1, pp. 40-48.

Li, X. (2016b), "The danger of Chinese exceptionalism”, Management and Organization Review, Vol. 12 No. 4, pp. 815-816.

Li, X. and Ma, L. (2015), "Management practices across countries: Converging in some aspects but diverging in others", Management and Organization Review, Vol. 11 No. 4, pp. 795-805.

Li, X., Worm, V. and Xie, P. (2015), "Solutions to organizational paradox: a philosophical perspective”, Copenhagen Discussion Papers No. 49, Asia Research Centre, Copenhagen Business School, Copenhagen.

Lin, D., Lu, J., Li, P.P. and Liu, X. (2015), "Balancing formality and informality in business exchanges as a duality: a comparative case study of returnee and local entrepreneurs in China", Management and Organization Review, Vol. 11 No. 2, pp. 315-342.

Losin, P. (1987), “Aristotle's doctrine of the mean”, History of Philosophy Quarterly, Vol. 4 No. 3, pp. 329-341.

Luo, Y. (2016), "Toward a reverse adaptation view in cross-cultural management", Cross Cultural \& Strategic Management, Vol. 23 No. 1, pp. 29-41.

McFarland, T. (2002), "Prolegomena", in McFarland, T. (Ed.), Opus Maximum: The Collected Works of Samuel Taylor Coleridge, Princeton University Press, Princeton, NJ, pp. xli-ccxl.

Mathews, J.A. and Tan, H. (2015), "Zhu Xi's neo-Confucian school: an organizational studies reading”, Asian Business \& Management, Vol. 14 No. 3, pp. 227-246.

Meyer, K.E. (2006), "Asian management research needs more self-confidence”, Asia Pacific Journal of Management, Vol. 23 No. 2, pp. 119-137.

Monastra, di G. (2000), "The "Yin-Yang" among the insignia of the Roman empire?", Sophia, 6(2) (it. ed. Futuro Presente, a. IV, N. 8, inverno 1996) (Trans. by John Monastra from the Italian).

Mueller, G.E. (1958), "The Hegel legend of 'thesis-antithesis-synthesis' ", Journal of the History of Ideas, Vol. 19 No. 3, pp. 411-414.

Nadar, L. (1990), Harmony Ideology: Justice and Control in a Zapotec Mountain Village, Stanford University Press, Stanford, CA.

Peng, K. and Nisbett, R. (1999), "Culture, dialectics, and reasoning about contradiction”, The American Psychologist, Vol. 54 No. 9, pp. 741-754.

Peng, K. and Nisbett, R.E. (2000), "Dialectical responses to questions about dialectical thinking", The American Psychologist, Vol. 55 No. 9, pp. 1067-1068.

Peng, M.W. (2003), "Institutional transitions and strategic choices", Academy of Management Review, Vol. 28 No. 2, pp. 275-296.

Peng, M.W. (2005), "Perspectives - from China strategy to global strategy", Asia Pacific Journal of Management, Vol. 22 No. 2, pp. 123-141.
Is Yin-Yang superior for paradox research? 
CCSM 25,3
Poole, M.S. and Van de Ven, A.H. (1989), "Using paradox to build management and organization theories", Academy of Management Review, Vol. 14 No. 4, pp. 562-578.

Pope, S. and Meyer, J.W. (2015), "The global corporate organization”, Management and Organization Review, Vol. 11 No. 2, pp. 173-177.

Redding, G. (2017), "Components and process in social science explanation: is there a role for Yin-Yang balancing”, Cross Cultural \& Strategic Management, Vol. 24 No. 1, pp. 152-166.

Redding, G. and Witt, M.A. (2015), "Advancing indigenous management theory: executive rationale as an institutional logic", Management and Organization Review, Vol. 11 No. 2, pp. 179-203.

Smets, M., Jarzabkowski, P., Burke, G. and Spee, P. (2015), "Reinsurance trading in Lloyd's of London: balancing conflicting-yet-complementary logics in practice", Academy of Management Journal, Vol. 58 No. 3, pp. 932-970.

Smith, W.K. and Lewis, M.W. (2011), "Toward a theory of paradox: a dynamic equilibrium model of organizing", Academy of Management Review, Vol. 36 No. 2, pp. 381-403.

Tsoukas, H. and Chia, R. (2002), "On organizational becoming: rethinking organizational change", Organization Science, Vol. 13 No. 5, pp. 567-582.

Tsui, A.S. (2004), "Contributing to global management knowledge: a case for high quality indigenous research", Asia Pacific Journal of Management, Vol. 21 No. 4, pp. 491-513.

Wong, W.C. (2006), "Understanding dialectical thinking from a cultural-historical perspective", Philosophical Psychology, Vol. 19 No. 2, pp. 239-260.

Zhang, Y., Waldman, D.A., Han, Y.L. and Li, X.B. (2015), "Paradoxical leader behaviors in people management: antecedents and consequences", Academy of Management Journal, Vol. 58 No. 2, pp. 538-566.

Zhou, X. (2012), "Mobilizational state: further exploration in the institutional logic of state governance in China (in Chinese, 运动型治理机制: 中国国家治理的制度逻辑再思考)”, Open Times (开放时代), Vol. 2012 No. 9, pp. 100-120.

Zhou, X. (2013), "State governance and the Chinese bureaucracy: a Weberian approach (in Chinese, 国 家治理逻辑与中国官僚体制: 一个韦伯理论角度)”, Open Times (in Chinese, 开放时代), Vol. 2013 No. 3, pp. 5-28.

\section{Corresponding author}

Xin Li can be contacted at: xl.int@cbs.dk

For instructions on how to order reprints of this article, please visit our website: 